\title{
Отсубстантивные имена действия с формантами отглагольных nomina actionis в современных русском и польском языках
}

\author{
ЕЛЕНА И. КОРЯКОВЦЕВА \\ Uniwersytet Przyrodniczo-Humanistyczny w Siedlcach, \\ Wydziat Humanistyczny, ul. Żytnia 39, PL - 08-110 Siedlce, Polska, \\ elena.koriakowcewa@gmail.com
}

\begin{abstract}
Namen članka je, da dokaže obstoj vrste izsamostalniških tvorjenk $\mathrm{s}$ pomenom dejanja (denominativna nomina actionis) z obrazilom -ование/-owanie v sodobnem ruskem in poljskem besedotvornem sistemu. V ta namen so bile analizirane njihove pomenske posebnosti in besedotvorne podstave. Avtorica se osredotoča na interakcijo med ustreznimi terminotvornimi in besedotvornimi modeli tovrstnih ruskih in poljskih tvorjenk, zbranih v slovarjih neologizmov. Analiza pa upošteva tudi številne besede iz sodobnih medijev, ki so se pojavile v zadnjih nekaj letih in še niso bile zajete $\mathrm{v}$ specializiranih slovarjih.
\end{abstract}

The aim of the article is to prove that there exist types of denominative nomina actionis with formants -ованиe/-owanie in contemporary Russian and Polish word-formation systems. In order to prove this, word-formation bases of denominative nomina actionis have been analysed and their semantic peculiarities have been obtained. The author focuses here on the interaction of term-formation models with the word-formation subsystems of Russian and Polish nomina actionis. The words are selected from Russian and Polish neological dictionaries. The analysis also covers a number of recent words found in the press that have emerged over the past several years and have not yet been listed in professional dictionaries.

Ključne besede: nomina actionis, termini, besedotvorno zgoščevanje, inovacije

Key words: nomina actionis, terms, word-formation compression, innovation 


\section{1 Вступление}

На рубеже XX-XXI веков обострилось внимание исследователей к причинам различных языковых изменений, их источникам, механизмам, движущим силам, тенденциям, направлениям и т. д. В частности, активно анализируются внешние и внутренние ресурсы развития лексической и словообразовательной подсистем, связанные с возрастанием коммуникативной роли терминологии. Отмечается, что в конце XX - начале XXI века заметно участились случаи использования в текстах СМИ деривационных аффиксов и аффиксоидов как в функции полнозначных слов-терминоидов, так и в функции терминоэлементов со специализированными значениями (Рацибурская 2003; Янко-Триницкая 2001: 476). „Автономное“ использование деривационного элемента, при котором особенно ярко проявляется его собственное значение, называется российскими учеными по-разному: „высвобождение аффикса“ (Земская 1996), „лексикализация аффикса“ (Журавлев 1982; Николина 2001), „эмансипация аффикса“ (Изотов 1998).

Следует отметить, что лексикализация аффиксов, а также их превращение в терминоэлементы - автономные носители общего значения той категории слов, в состав которых они входят, - явление далеко не уникальное, не ограниченное рамками одного языка, в данном случае - русского. Так, например, не только в русском, но и в польском языке известны примеры самостоятельного использования в обобщенном значении „течение, доктрина“ суффикса -izm (ср. -изм), греко-латинского по происхождению, с помощью которого во многих языках образуются названия идеологических и научных направлений (см. http://sjp.pl/izm). Анализируя примеры лексикализации аффиксов в английском языке, Вальтер фон Вартбург описал процесс превращения суффикса -ade в самостоятельное слово (см.: Арутюнова 1961: 99-100). Этот суффикс, выделившись из слов lemonade, orangeade ('лимонад'), с середины XX века начал сам по себе обозначать напиток из фруктов: „Have you some ade?“ / „У вас есть какой-нибудь напиток?““

Какие же факторы способствуют превращению служебной морфемы (аффикса) в слово? Известно, что в „словарной“ части языковой способности человека существуют эталоны восприятия аффиксов, составляющие вместе с эталонами восприятия корней словообразовательный компонент внутреннего лексикона. Эталоны восприятия продуктивных словообразовательных аффиксов наиболее близки к эталонам восприятия корневых морфем (Гараева 1987). Очевидно, по этой причине продуктивные аффиксы, передающие категориальные значения, способны выступать как классификаторы, маркеры этих значений (см. Drews 1989; Кубрякова 1991; Вендина 1994). Высокая продуктивность и монофункциональность аффикса способствуют его лексикализации либо превращению в продуктивный терминоэлемент - автономный носитель категориального значения. Пример тому - процесс превращения в терминоэлементы монофункциональных формантов русских и польских отглагольных nomina 
actionis с финалями -ованиј(е), -ированиј(е), -изированиј(е), -оwanie. С помощью этих терминоэлементов, являющихся автономными носителями процессуального значения, создаются отсубстантивные nomina actionis в русском и польском языках, хотя в их словообразовательных подсистемах идентичные деривационные процессы, как будет показано в данной статье, развёртывались с разной интенсивностью и скоростью.

\section{2 Русские отсубстантивные имена действия с формантом -ование/-ирование}

Семантика и особенности функционирования словообразовательных моделей „существительное + -ирование“, „существительное +-ование/ -евание“, по которым образуются термины процессов, достаточно хорошо изучены специалистами по русской терминологии (см.: Винокур 1939; Даниленко 1977; Канделаки 1977). Эти модели стали продуктивными в терминосистеме к 30-м гг. XX в., однако их формирование началось, очевидно, во второй половине XIX века. Именно к этому периоду относится появление окказиональных отыменных имен действия типа итальянизирование, мужикование, обнаруженных в переписке деятелей русской культуры: „итальянизирование ( $\longleftarrow$ итальянский) русских напевов“ - при отсутствии глагола итальянизировать (П. И. Чайковский - С. В. Флерову, 04.04. 1881 г. ПСС, т. 10: 130-131); „,ппециалист по мужикованию“, т.е. 'защитник политических прав мужика, крестьянина' (В. М. Гаршин Е. М. Гаршиной, 24.02.1882 г. ПСС, т. 3: 247).

В русском языке второй половины XIX века единичные индивидуально-авторские образования типа итальянизирование, мужикование были несистемными окказионализмами, поскольку они создавались с нарушением норм построения имен действия на -ние. Однако норма, явление конкретно-историческое, может изменяться под влиянием продуктивных словообразовательных процессов, происходящих в системе общенародного языка или в отдельных его подсистемах. Уже к 30-ым годам XX века в русской терминологии оформилась достаточно многочисленная группа отыменных имен действия с формантами -ование/-евание, -ирование, -изирование (см.: Винокур 1939). Появление этих формантов было обусловлено преобразованием опосредствованной именной мотивации в непосредственную у имен действия - терминов процессов превращения типа скирдование (скирдовать, скирда), терминов покрытия типа обетонирование (обетонировать, бетон). Термины процессов создаются сознательно, с целью указания на ближайшее родовое понятие и на признак - видовое понятие. Например: брикетирование „процесс превращения различных мелких материалов в куски - брикеты"“, обетонирование „процесс покрытия чего-л. бетоном со всех сторон, по всей поверхности“. В терминологических дефинициях отглагольные имена превращение и покрытие указывают на ближайшие родовые понятия, а существительные брикет

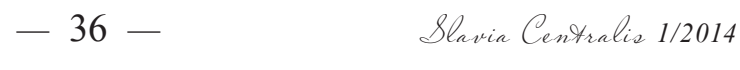


и бетон - на видовые отличия. В терминах процессов на -ние смысловая граница идет по именной основе. В таких условиях становится неизбежной трансформация отглагольных словообразовательных моделей, по которым образуются термины - имена действия -, в модели отыменные (см.: Канделаки 1977: 152).

Переразложение основ имен действия на -ние - явление не новое для славянских языков. О возможности переразложения основ существительных на -ние ещё в общеславянском языке писал Антуан Мейе: „Отвлеченные существительные могут быть образованы и от причастий, восстанавливаемых лишь теоретически; так, от глагола несовершенного вида Увнвати мы находим Увнваннє, хотя страдательное причастие прошедшего времени вряд ли существовало“ (Мейе 1951: 217).

Переразложение основ терминов - отглагольных имен действия на -ирование, -изирование,-ование/-евание -, обусловленное существованием устойчивых моделей составов значений, а также чёткими смысловыми отношениями, существующими между составом значений терминов и их звуковыми оболочками, явилось причиной образования вторичных суффиксов -изированиј-, -ированиј-, -ованиј- и формирования отыменных словообразовательных моделей имен действия с этими суффиксами (см.: Канделаки 1977: 153). Формирование вторичных суффиксов -ированиј-, -изированиј-, -ованиј- отвечает тенденции к фонетическому наращению суффиксов, обладающих максимальной продуктивностью (в данном случае - суффикса -ниј-).

Вторичные суффиксы, сформировавшиеся на базе высокопродуктивного монофункционального суффикса отглагольных существительных -ниј-, искусственно внедрялись в отраслевые терминологии с целью расширения деривационной базы терминов процессов. Отыменные nomina actionis образуются с помощью этих вторичных суффиксов как субституты тождественных им по значению синтаксических конструкций, где имя в именительном падеже, выражающее ближайшее родовое понятие, управляет существительным или субстантивным словосочетанием, на базе которого образуется термин процесса. В специалистических текстах замене однословными терминами процессов чаще всего подлежат следующие синтаксические конструкции (см.: Канделаки 1977: 36-37):

1) „имя действия в им. п. + управляемое имя существительное или субстантивное словосочетание в тв.п.“: „мягчение + отрубным киселем“ $\rightarrow$ киселевание;

2) „имя действия в им. п. + управляемое имя существительное или субстантивное словосочетание в род. п.“: „нанесение + annepema“ $\rightarrow$ аппертование;

3) „имя действия в им.п. + управляемое им предложно-падежное или субстантивное словосочетание со значением места“: „обработка в автоклаве“ $\rightarrow$ автоклавирование; „отжим в иеентрифуге“ $\rightarrow$ ичентрифугирование; 
4) „имя действия в им. п. + управляемое им предложно-падежное словосочетание в род. п.“: „способ обработки + посредством фррез“ $\rightarrow$ фрезование;

5) „имя действия в им. п. + управляемое им предложно-падежное словосочетание в вин. п. со значением места“: „пропускание + через шприцмашину“ $\rightarrow$ шприцевание;

6) „имя действия в им. п. + управляемое им предложно-падежное словосочетание в тв. П. со значением места“: „способ обработки между вальияами" $\rightarrow$ вальиевание.

В терминах процессов типа автоклавирование, скирдование основная смысловая нагрузка приходится на финали -ирование, -ование, так как именно с их помощью получает формальное выражение ядерная процессная сема. Значения именных производящих основ лишь конкретизируют процессное значение, передаваемое формантами. Смысловая „нагруженность“ финалей терминов процессов типа автоклавирование, скирдование способствовала превращению этих финалей, состоящих из двух суффиксов - глагольного и высокопродуктивного именного -, в один протяженный суффикс. Структурные элементы -ирова-, -ова-, материально тождественные суффиксам глаголов несовершенного вида, вносят в семантику вторичных формантов -ование, -ирование оттенок ,длительность“. С помощью суффиксальных терминоэлементов с „автономным“ значением длительного процесса nomina actionis стали образовываться от основ идентифицирующих существительных, в значениях которых отсутствует процессуальная сема.

В 60-70-е гг. ХХ в. усилилась продуктивность терминоэлементов с высокой степенью лексической наполненности: -ование/-евание, -ирование/изирование (см.: Даниленко 1977). В период с конца 60-х до середины 80-х гг. с помощью этих формантов, по имеющимся данным, было образовано около 40 отсубстантивных имен действия - терминов процессов, которые в результате т. н. интеллектуализации языка вошли в общее употребление и поэтому были отмечены словарями новых слов: валкование, дождевание (НС3-60); биркование, бороздование, лоббирование, лункование (НС3-70); алгоритмирование (НРЛ-77), картирование (НРЛ-79); логизирование (НРЛ-80); неглижирование, шутование (НРЛ-84) и др.

Отсубстантивные имена действия на -ование, подобно отглагольным дериватам типа синхронизирование, могут сочетаться с большинством лексико-синтаксических показателей процессуального значения, ${ }^{1}$ а именно:

1) с фазовыми глаголами (закончить биркование, картирование);

2) с глаголами, указывающими на изменение характера протекания процесса (отложить бороздование, картирование, лункование);

${ }^{1}$ О показателях процессуального значения существительных подробнее см. (Коряковцева 1998: 41-44). 
3) с глаголами, обозначающими противодействие (препятствовать шутованию); 4) с глаголами, указывающими на уклонение от участия в процессе (воздержаться от логизирования, неглижирования, шутования);

5) с глаголами, указывающими на преднамеренность процесса (планировать алгоритмирование, бороздование, картирование);

6) с глаголами, обозначающими воздействие на субъект с целью привлечения к совершению процесса или отстранения от совершения процесса (запретить биркование, лункование).

Как и отглагольные nomina actionis, отыменные имена действия с формантами -ирование, -изирование, -ование/-евание) могут управлять зависимыми формами со значением объекта действия. Ср: „Организация ежегодно щедро отсчитывает пятьдесят тысяч долларов на лоббирование своих идей в конгрессе США“ (Правда, 02.10.1974 г.), „неправильное биркование скота“ (Сельская жизнь 13.10.1973 г.), „бороздование полей“ (Известия, 19.03.1971 г.).

В 90-е годы XX века продуктивность отыменных словообразовательных моделей с суффиксами -ованиј-, -ированиј-, -изированиј- в профессионально-разговорной русской речи заметно снизилась, что нашло отражение в языке прессы. Так, в периодике 90-х годов нами обнаружены только два окказионализма-псевдотермина с формантами -ирование, -ование: интеллигентизирование 'превращение в интеллигента' („Одновременно проводится „интеллигентизирование“ - все поголовно повышают свои знания до уровня выпускников вузов“// КП, 20.03.1990), дуракование 'нарочитое безделье' - отыменное имя процесса, семантически тождественное фразеологизму валять дурака (,...бездельничание, дуровакование месяцами...“ // „Магазин. Иронический журнал“. Москва, 1991. Вып. 2, c. 9).

К началу XXI века в общелитературном языке угасла эмпирическая продуктивность отыменных словообразовательных моделей с терминоэлементами -ирование, -изирование, -ование: как показал поиск в интернет-базе Национального корпуса русского языка, в период с середины 90-х гг. XX в. до конца 2013 года по данным моделям неологизмы не были образованы. По всей видимости, угасание эмпирической продуктивности словообразовательных моделей nomina actionis с суффиксами -ирование, -ование было обусловлено возросшей конкуренцией со стороны активных и высокопродуктивных синонимических отыменных словообразовательных типов с суффиксом -изащиј-: только в период с 1990 по 2010 год появилось около 100 новых отсубстантивных имен действия на -изациия (Коряковцева 2010). 


\section{3 Польские отсубстантивные имена действия с формантом -owanie}

Отыменные имена действия с формантом -owanie, по нашим данным, не были предметом специального исследования в трудах польских дериватологов. Есть основания полагать, что этот тип nomina actionis развивался по тому же пути, что и русские имена действия с формантом -ование. Случаи образования имен действия с формантом -owanie от основ существительных, минуя глагольную ступень, известны уже в XIX веке, например в переписке Б. Пруса: gangrenowanie ( $\leftarrow$ gangrena), ,gangrenowanie mowy ojczystej“ (Bolesław Prus, Kroniki, t. II: 653-654).

В словарях неологизмов, подготовленных к печати Институтом польского языка Польской академии наук, отмечены десятки имен действия с формантом -owanie, не соотносительных с однокоренными глаголами на -ować. Бо́льшая часть nomina actionis с формантом -owanie - это термины процессов, попавшие в язык газет из профессиональной разговорной речи. Среди них можно выделить следующие семантические разряды терминов:

1) со значением 'обработка объекта указанным или при помощи указанного вещества': kwasowanie $\leftarrow$ kwas (,...płukanie studni kwasami... kwasowanie studni“: NSP'1: 128), ср. русск. квасцевание, киселевание;

2) со значением 'помещение объекта в указанный вид упаковки': celofanowanie $\leftarrow$ celofan (,celofanowanie i układanie bombonier": $\mathrm{NSP}^{2}$ I: 82); paletyzowanie $\leftarrow$ paleta (,Koszt paletyzowania takiego ładunku obciąża armatora“: NSP' II: 8), taśmowanie $\longleftarrow$ taśma (,,aparat do taśmowania bednarką“: NSP² II: 228), ср. русск. пакетирование;

3) со значением 'введение указанной составной части в объект': amonowanie $\leftarrow$ amon (,próby amonowania serwatki“: $\mathrm{NSP}^{1} \mathrm{I}:$ 15), fluorkowanie $\leftarrow$ fluorek (,fluorkowanie wody pitnej“: NSP' I: 83), olejowanie $\leftarrow$ olej (,dalsze prace nad olejowaniem i granulacją nawozu“" NSP' I: 191), ozonizowanie $\leftarrow$ ozon (,ozonizowanie powietrza“: $\mathrm{NSP}^{1} \mathrm{I}$ : 197), ср. русск. озонирование, фторирование;

4) со значением 'покрытие указанным объекта': asfaltobetonowanie $\leftarrow$ asfaltobeton ,układanie nawierzchni z asfaltobetonu“": $\left.\mathrm{NSP}^{1} \mathrm{I}: 26\right)$, ср. русск. асфальтирование;

5) со значением создания: harmonogramowanie $\leftarrow$ harmonogram (,zasady harmonogramowania pracy“: $\mathrm{NSP}^{1}$ I: 94), ср. русск. группирование;

6) со значением 'сообщение объекту новой указанной форм': profilowanie $\leftarrow$ profil (,profilowanie odwiertu“: NSP' I: 193), ср. русск. профилирование;

7) со значением 'удаление указанного признака у объекта': odazotowanie $\leftarrow$ azot (,odazotowanie gazu ziemnego": $\mathrm{NSP}^{1}$ I: 181), odfenolowanie $\leftarrow$ fenol („ludowa metoda odfenolowania koksowniczych wód ściekowych“: NSP' $^{1}$ I: 182), odszypułkowanie $\longleftarrow$ szypułka (,odszypułkowanie truskawek i malin“: NSP'1: 186), ср. русск. обезгаживание;

8) со значением 'удаление из указанного объекта': odkopcowanie $\leftarrow$ kopiec 'wydobycie z kopca': NSP' I: 183). 
По аналогии с перечисленными выше терминами в разговорной речи образуются псевдотермины ${ }^{2}$ - терминоподобные лексические единицы, которые не могут иметь дефиниции в определенной терминологической подсистеме: barowanie $\leftarrow$ bary 'branie się za bary, zmaganie się z czymś' ( $\mathrm{NSP}^{2}$ I: 55); blondynkowanie $\leftarrow$ blondynka 'granie ról słodkich blondynek, tzn. ładnych, naiwnych dziewczątek'(NSP ${ }^{2}$ I: 72); dachowanie $\leftarrow$ dach 'przewrócenie się samochodu na dach w czasie wypadku' ( $\mathrm{NSP}^{2} \mathrm{I}$ : 106); felietonowanie $\leftarrow$ felieton 'pisanie lub wygłaszanie felietonów' (NSP² I: 81); festiwalowanie $\leftarrow$ festiwal 'odbywanie się, trwanie festiwalu' (NSP² I: 161), kolejkowanie $\leftarrow$ kolejka 'stanie w kolejce' (NSP' I: 115), tokciowanie $>$ łokieć 'przepychnie się za pomocą łokci' (NSP' I: 135); ogonkowanie $\leftarrow$ ogonek 'stanie w ogonku, tzn. w kolejce'( $\mathrm{NSP}^{2} \mathrm{I}$ : 115); panbratowanie $\leftarrow$ pan brat 'bycie z kimś za pan brat; poufałość' (NSP' II: 8); placówkowanie placówka 'praca na placówce zagranicznej'(NSP2 II: 16), plastykowanie $\leftarrow$ plastyki 'ironicznie o upowszechnianiu sztuk plastycznych przez umieszczanie np. rzeźb na ulicach, podwórkach itp.' (NSP ${ }^{2}$ II: 16); plombowanie $\leftarrow$ plomba 'budowanie plomb, tzn. nowych budynków w ciągu starej zabudowy' (NSP² II: 33); poezjowanie $\leftarrow$ poezja 'pisanie wierszy', „...w ciągu dwudziestu lat swojego poezjowanie wydał dziesięć tomów“" Lit 10/ 1988 r. (NSP² II: 43); pomnikowanie $\leftarrow$ pomnik 'masowe budowanie pomników' (NSP ${ }^{2}$ II: 52); punkowanie $\leftarrow$ punk 'bycie punkiem' ( $\left.\mathrm{NSP}^{2} \mathrm{II}: 107\right)$; rocznicowanie $\leftarrow$ rocznica 'obchodzenie rocznic, jubileuszy'( $\left.\mathrm{NSP}^{2} \mathrm{II}: 128\right)$; satyrykowanie $\leftarrow$ satyryk 'uprawianie twórczości satyrycznej, kabaretowej' (NSP'2 II: 148); skatowanie $\leftarrow$ англ. skate, skater 'jazda na deskorolce' (NSP² II: 164); społkowanie $\leftarrow$ spótka (okazj., żart.) 'zakładanie spółek, handlowych, przemysłowych itp.' (NSP ${ }^{2}$ I: $185)$; sprayowanie $\leftarrow$ spray 'malowanie napisów na murach sprayem' ( $\mathrm{NSP}^{2}$ II: 186); stypendiowanie $\leftarrow$ stypendium 'przydzielanie stypendiów' ( $\mathrm{NSP}^{2}$ II: 198); taktyzowanie > taktyka 'przywiązywanie nadmiernej wagi do stosowania taktyki' (NSP' II: 227); szwagrowanie $\leftarrow$ szwagier 'bycie szwagrem' ( $\mathrm{NSP}^{2}$ II: 220); zięciowanie $\leftarrow$ zięć 'bycie zięciem', por. „A w tym wszystkim ogromna rola rodziny: szwagrostwo, zięciostwo. To zięciowanie, szwagrowanie, obdarzanie się rozmaitymi medalami, jest wodewilowo prześwietne“. Żywot Warszawy, nr 301-302/1991 r. (NSP² II: 220).

Среди псевдотерминов - существительных с процессуальными значениями - выделяется серия слов, мотивированных названиями лиц по должности или роду занятий, которые имеют значение 'выполнение функций, занятие того, кто назван мотивирующим личным существительным': dziekanowanie $\leftarrow$ dziekan, kustoszowanie $\leftarrow$ kustosz, marszałkowanie $\leftarrow$ marszałek, prezydentowanie $\leftarrow$ prezydent, rektorowanie $\leftarrow$ rektor, reporterowanie $\leftarrow$ reporter $\left(\mathrm{NSP}^{1}\right)$, wojewodowanie $\leftarrow$ wojewoda $\left(\mathrm{NSP}^{2}\right)$.

Ряд неологизмов - имен действия с формантом -owanie - имеют свойства прототерминов - рабочих названий терминируемых понятий, ср.: 2 О ономасиологических типах т. н. „специальных слов“ подробнее см. (Nowakowski
2000: 201-204). 
czadowanie (środ.) 'wykonanie muzyki rockowej maksymalnie głośno, z jak największą ekspresją' (NSP ${ }^{2}$ I: 99) $\leftarrow$ czad (środ.) 'głośna, ekspresywna muzyka, głównie rockowa'; czworakowanie $\leftarrow$ czworaki (środ.) 'chodzenie na czworakach’, cp.: „Program w przedszkolach przewiduje - w ramach zajęć preferujących wychowanie fizyczne dziecka - tzw. czworakowanie“. Sygnat 50/1985 r. (NSP² I: 103); rozśrodkowanie $\longleftarrow$ środek (środ.) 'przeniesienie kogoś z centrum na prowincję', cp.: „,..przymusowe rozśrodkowanie nauczycieli, a więc przeniesienie kadry pedagogicznej z miasta na wieś'،. Tygodnik Kulturalny 27/1987 r. (NSP² II: 134); roztowarowanie $\leftarrow$ towar (środ.) 'opróżnienie sklepu z towaru' (NSP2 II: 134). Эти существительные с процессуальными значениями в словарях неологизмов имеют помету, указывающую на их принадлежность к разговорно-профессиональному стилю, а также дефиницию с поясняющим словосочетанием ,так называемый“.

Инновацией в области nomina actionis с терминоэлементом -owanie является образование пейоративизмов от фамилий государственных и политических деятелей современной Польши, наблюдаемое в языке прессы и интернет-СМИ: kaczorowanie $(\leftarrow$ Kaczor $\leftarrow$ Kaczyński - прозвище президента Л. Качиньского) 'поведение, типичное для президента Л. Качиньского', lepperowanie 'образ действий, типичных для А. Леппера' ( $\leftarrow$ Lepper, cp.: „Mnie nie odpowiada taki sposób lepperowania Polski...“"Angora, 2001 r., № 42, s. 16), macierewiczowanie ( $\leftarrow$ Macierewicz) 'поведение, типичное для политика А. Мацеривича', napieralskowanie ( $\leftarrow$ Napieralski) 'поведение, типичное для политика А. Наперальского', tuskowanie (ŁTusk) 'поведение, типичное для Д. Туска, премьер-министра Польши’, ср.: „...tuskowanie to agresja nie znająca granic" - http://forum.gazeta.pl/forum/w,29,70790581, 70790581,_tuskowanie_html).

\section{4 Выводы}

Анализ nomina actionis с финалями -ование, -оwanie, зафиксированных в русских и польских неологических словарях, а также в интернет-базах, показал, что образование отсубстантивных имен действия с помощью суффиксальных терминоэлементов (русск. -ирование, -изирование, -ование, польск. -owanie) наблюдается в обоих сопоставляемых языках. Факторами, способствовавшими превращению вторичных производных суффиксов -ирование, -изирование, -ование, -оwanie в терминоэлементы - автономные носители процессного значения, - являются:

1) высокая продуктивность и монофункциональность суффиксов -ниј(е), -ni(e), передающих категориальное значение процесса;

2) актуализация опосредованной именной мотивации nomina actionis c финалями -ование, -owanie, обусловленная тенденцией к согласованию семантической структуры с внешней формой терминов процессов с формантами -ниј(e), -ni(e), образованных от отыменных глаголов. Смысловая „нагруженность“ финалей отглагольных терминов процессов 
типа скирдование, odpratkowanie обусловила превращение этих финалей во вторичные протяженные суффиксы - своеобразные терминоэлементы с автономным процессуальным значением.

Эталоны восприятия вторичных суффиксов -изирование/-ирование, -ование, -owanie как „автономных“ носителей процессуального значения сформировались прежде всего в сознании ученых - „пользователей“ и творцов терминов. В конце XX века в связи с т. н. „интеллектуализацией“ языка и активизацией тенденции вербальной экономии резко возросла потребность в компактных языковых средствах. В связи с необходимостью компрессии текстов в различных стилях языка и речи появились имена действия, созданные по моделям отыменных терминов процессов с помощью формантов -ирование/-изирование, -ование, -изация, -оwanie, -yzowanie, -izacja, ставших суффиксальными терминоэлементами (см. Коряковцева 2000, 2001, 2010). Активное использование терминоэлементов с автономным процессуальным значением, отражающее динамичность мышления современных носителей русского и польского языка, помогает „снять“" всевозможные ограничения на словопроизводство процессных имен. Регулярность образования отсубстантивных nomina actionis c помощью суффиксальных терминоэлементов свидетельствует о росте агглютинативности в семантике русских и польских дериватов, т. е. о росте отношений взаимооднозначности между означаемым и означающим, что способствует расчлененности слов на морфемы: с каждой морфемой связывается определенная часть значения слова (расчлененность семантическая поддерживает расчлененность структурную).

Отмечая конвергентность развития аналогичных моделей отыменных nomina actionis с терминоэлементами -ование и -owanie в русском и польском языках, следует, однако, подчеркнуть, что эти модели обладают разной активностью и продуктивностью. Так, суффикс польских отсубстантивных имен действия -owanie обладает значительно бо́льшей активностью и более высоким стилистическим потенциалом, чем изофонный суффикс русских nomina actionis -ованиј(е). Лексическая база для создания польских отыменных имен действия на -owanie значительно шире, чем у русских словообразовательных типов с формантами -ирование, -изирование, -ование/-евание. Польские nomina actionis на -owanie образуются не только от конкретно-предметных и вещественных существительных (как русские имена действия на -ование), но также и от названий литературных жанров (felietonowanie, poezjowanie), от названий болезней (gangrenowanie), от фамилий (lepperowanie, tuskowanie), от названий лиц: а) по занимаемой должности (dziekanowanie, rektorowanie), б) по степени родства (szwagrowanie, zięciowanie), в) по типу внешности (blondynkowanie), г) по принадлежности к неформальной организации (punkowanie), д) по профессии и роду занятий (reporterowanie, satyrykowanie). С помощью форманта -owanie существительные с процессуальным значением свободно образуются от экзотизмов-трансплан- 
тантов (skatowanie $\leftarrow$ англ. skate, skater, sprayowanie $\leftarrow$ англ. spray), а также от фразеологизмов (panbratowanie 'bycie z kimś za pan brat'). В русском языке такой практически ничем не ограниченной продуктивностью характеризуются словообразовательные модели отыменных nomina actionis с интернациональным суффиксом -изация, вытеснившие модели с терминоэлементом -ование. Польский язык, в отличие от русского, более активно использует исконный формант -owanie, хотя изофонный суффикс -izacja также является продуктивным.

\section{ЛИТЕРАТУРА}

Нина Д. АРУТЮНОВА, 1961: Очерки по словообразованию в современном испанском языке. Москва: Издательство АН СССР.

Татьяна И. ВЕНДИНА, 1994: Семантическая функция суффикса и сопоставительное изучение славянского словообразования. Теоретические и методологические проблемы сопоставительного изучения славянских языков. Отв. ред. Г. П. Нещименко. Москва: Наука. 80-92.

Григорий О. ВИНОКУР, 1939: О некоторых явлениях словообразования в русской технической терминологии. Труды МИФЛИ. Сборник статей по языкознанию. Москва, т. V.

Людмила И. ГАРАЕВА, 1987: Психолингвистический анализ семантической структуры производного слова: Автореферат дисс...канд. филол. наук. Москва.

Валерия П. ДАНИЛЕНКО, 1977: Русская терминология. Москва: Издательство AH CCCP.

Анатолий Ф. ЖУРАВЛЕВ, 1982: Технические возможности русского языка в области предметной номинации. Способы номинации в современном русском языке. Отв. ред. Д.Н. Шмелев. Москва: Наука. 45-109.

Елена А. ЗЕМСКАЯ, 1996: Активные процессы современного словопроизводства. Русский язык конща ХХ столетия (1985-1995). Отв. ред. Е. А. Земская. Москва: Языки русской культуры.

Владимир П. ИЗОТОВ, 1998: Параметры описания системы способов русского словообразования (на материале окказиональной лексики русского языка). Орел: Издательство Орловского государственного университета.

Татьяна Л. КАНДЕЛАКИ, 1977: Семантика и мотивированность терминов. Москва: Наука.

Елена И. КОРЯКОВЦЕВА, 1998: Имена действия в русском языке: история, словообразовательная семантика. Москва: Издательство Института русского языка РАН.

- -, 2000: Существительные с формантом -изация/-іzacja в русском и польском языках. Stowo. Tekst. Czas. Red. Michaił Aleksiejenko. Szczecin: Wydawnictwo Uniwersytetu Szczecińskiego. Tom IV. 152-155. 
--, 2001: Заимствование как средство обогащения словообразовательной системы русского языка. Stowo. Tekst. Czas. Red. Michaił Aleksiejenko. Szczecin: Wydawnictwo Uniwersytetu Szczecińskiego. Tom V. 208-211.

- -, 2010: Производные nomina actionis и языковой образ постсоциалистического общества (на материале русского, польского и чешского языков). Відображення історії та культури народу в словотворенні. Ред. Н.Ф. Клименко, Є. А. Карпіловська. Київ. 133-144.

Елена С. КУБРЯКОВА, 1991: Проблема соотношения внутреннего лексикона с морфологией и словообразованием. Человеческий фактор в языке: Язык и порождение речи. Отв. ред. Е.С. Кубрякова, А.М. Шахнарович, Л.В. Сахарный. Москва: Наука. 113-123.

Антуан МЕЙЕ, 1951: Общеславянский язык. Москва: Издательство иностранной литературы.

Наталья А. НИКОЛИНА, 2001: От морфемы к слову. Языковая деятельность: переходность и синкретизм. Москва-Ставрополь: Издательство Ставропольского государственного университета. (Сборник статей научно-методического семинара „TEXTUS“, 7). 54-58.

Лариса В. РАЦИБУРСКАЯ, 2003: Особенности новообразований в современных средствах массовой информации. http://www.unn.ru/pages/e-library/ vestnik/99990196_West_filol_2003_1(3)/B_3-3.pdf

Надия А. ЯНКО-ТРИНИЦКАЯ, 2001: Словообразование в современном русском языке. Москва: Индрик.

Etta DREWS 1989: Die Bedeutung von Morphemen für die Sprachanalyse: zur mentalen Verarbeitung lexikalischer und grammatischer Morpheme. Opladen: Westdeutscher Verlag.

Jacek NOWAKOWSKI, 2000: Typy onomazjologiczne wyrazów specjalnych. Słowo. Tekst. Czas. Red. Michaił Aleksiejenko. Szczecin: Wydawnictwo Uniwersytetu Szczecińskiego. Tom IV. 201-204.

\section{СЛОВАРИ И СПИСОК СОКРАЩЕНИЙ}

КП - газета „Комсомольская правда“, Москва.

ЛГ - газета „Литературная газета“, Москва.

НС3-60 - Новые слова и значения. Словарь-справочник по материалам прессы и литературы 60-х гг. Москва, 1971.

НС3-70 - Новые слова и значения. Словарь-справочник по материалам прессы и литературы 70-х гг. Москва, 1984.

НРЛ-77 - Новое в русской лексике. Словарные материалы - 1977. Москва, 1980.

НРЛ-78 - Новое в русской лексике. Словарные материалы - 1978. Москва, 1981. 
НРЛ-79 - Новое в русской лексике. Словарные материаль - 1979. Москва, 1982.

НРЛ-80 - Новое в русской лексике. Словарные материаль - 1980. Москва, 1984.

НРЛ-81 - Новое в русской лексике. Словарные материаль - 1981. Москва, 1986.

НРЛ-82 - Новое в русской лексике. Словарные материаль - 1982. Москва, 1986.

НРЛ-83 - Новое в русской лексике. Словарные материаль - 1983. Москва, 1987.

НРЛ-84 - Новое в русской лексике. Словарные материаль - 1984. Москва, 1989.

ПСС - Полное собрание сочинений.

$\mathrm{NSP}^{1}$ - Nowe stownictwo polskie: materiaty z prasy lat 1971-1981. Wrocław-Warszawa etc., 1989, cz. 1-2.

$\mathrm{NSP}^{2}$ - Nowe stownictwo polskie: materiaty z prasy lat 1985-1992. Wrocław-Warszawa etc., 1998, cz. 1-2.

\section{НЕТОГРАФИЯ}

Национальный корпус русского языка - http://www.ruscorpora.ru/search-main.html Narodowy Korpus Języka Polskiego - http://nkjp.pl/poliqarp/

Słownik Języka Polskiego - http://sjp.pl/

\section{IZSAMOSTALNIŠKE TVORJENKE Z OBRAZILI IZGLAGOLSKIH TVORJENK S POMENOM DEJANJA V RUŠČINI IN POLJŠČINI}

Namen članka je opraviti celovito analizo pomenskih kategorij in tvorbenih vzorcev izsamostalniških tvorjenk s pomenom dejanja (denominativna nomina actionis), ki vsebujejo glagolsko pripono -oвa-/-owa-.

Prvi del članka je posvečen kratekemu opisu značilnosti morfemske leksikalizacije. Drugi in tretji del pa vsebujeta pomenski in morfološki opis besedotvornih procesov s sekundarnimi obrazili -ование/-owanie v sodobnem ruskem in poljskem jeziku. Avtorica posebno pozornost namenja tvorbi novejših terminov in se osredotoči na opis besedotvornih vzorcev v znanstvenem jeziku; ugotavlja, da se specializirano strokovno kodiranje izvaja s pomočjo sekundarnih besedotvornih obrazil, tj. -ование/-owanie. Izglagolske samostalniške tvorjenke s pomenom dejanja in z obrazilom -ование/-оwanie navadno vsebujejo glagolsko pripono -овa-/-owa-. Avtorica določa dejavnike, ki odločajo o izglagolskih značilnostih takih samostalniških tvorjenk, in ugotavlja, da po eni strani izgubijo nekaj glagolskih oblikoskladenjskih lastnosti, po drugi strani pa pridobijo več samostalniških.

Izhajajoč iz strukturne analize takih tvorjenk, avtorica predstavi vrsto dejavnikov, ki odločajo o njihovih značilnostih. Med njimi so najpomembnejši: (1) morfološke značilnosti besedotvorne podstave in njihova vloga $v$ tvorbenem procesu, (2) pomen

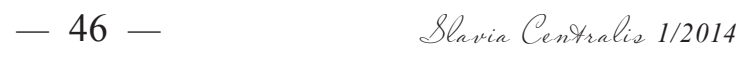


tvorjenke v odnosu do motivirajoče beside, (3) tvorbene zmožnosti in (4) druge v študiji izpostavljene morfološke kategorije.

Upoštevan je tudi skladenjski vidik, saj je sintagma temeljnega pomena za besedotvorno analizo. Pretvorba skladenjske podstave v tvorjenko namreč deluje v smeri od skladenjsko-pomenske $\mathrm{k}$ novi morfološki in morfemski površinski strukturi v sodobni ruščini in poljščini, tj. -ованиe/-owanie. S tema obraziloma se tovrstne tvorjenke pogosto izpeljujejo v sodobnih ruskih in poljskih besedilih množičnih medijev. 